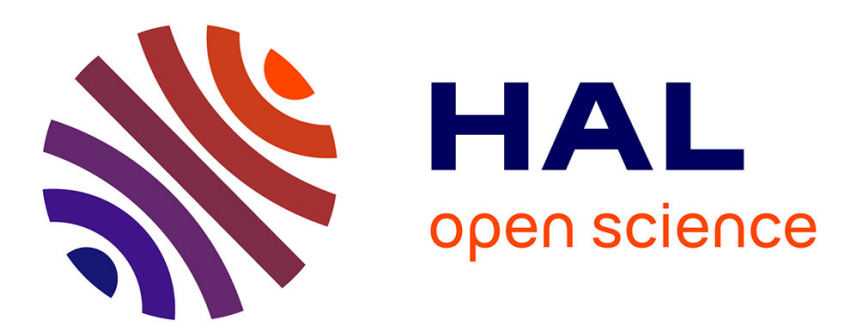

\title{
Per Peers Learning Education Approach to Teach Industrial Test to Undergraduate Students
}

\author{
Béatrice Pradarelli, Pascal Nouet, Laurent Latorre
}

\section{To cite this version:}

Béatrice Pradarelli, Pascal Nouet, Laurent Latorre. Per Peers Learning Education Approach to Teach Industrial Test to Undergraduate Students. EWME: European Workshop on Microelectronics Education, May 2016, Southampton, United Kingdom. 10.1109/EWME.2016.7496485 • lirmm-01385619

\section{HAL Id: lirmm-01385619 \\ https://hal-lirmm.ccsd.cnrs.fr/lirmm-01385619}

Submitted on 21 Oct 2016

HAL is a multi-disciplinary open access archive for the deposit and dissemination of scientific research documents, whether they are published or not. The documents may come from teaching and research institutions in France or abroad, or from public or private research centers.
L'archive ouverte pluridisciplinaire HAL, est destinée au dépôt et à la diffusion de documents scientifiques de niveau recherche, publiés ou non, émanant des établissements d'enseignement et de recherche français ou étrangers, des laboratoires publics ou privés. 


\title{
Per Peers Learning Education Approach to Teach Industrial Test to Undergraduate Students
}

\author{
Beatrice Pradarelli, Pascal Nouet, Laurent Latorre \\ University of Montpellier \\ Polytech Montpellier/LIRMM/Montpellier CNFM center \\ Montpellier, FRANCE \\ beatrice.pradarelli@lirmm.fr
}

\begin{abstract}
This paper presents a return of experience relative to per peers learning approach to teach industrial test of integrated circuits (IC) to undergraduate students from Polytech Montpellier, using the test platform of the CNFM. The objectives of this innovative approach are double: technical and educational. The students have to acquire knowledge and competencies about IC testing (test methods, test program development, debugging, diagnosis, test results and graph analysis technics) in a way they are the protagonists of their own learning and the one of their peers. A specific course organization has been put in place as well as dedicated training materials combining quizzes and video tutorials have been developed to guide the students achieving this new role. A course evaluation form has been created, based on the F2A Louvain University one, to help the students providing classifiable feedback about this new educational approach. The analysis of the students' exam results is presented.
\end{abstract}

Keywords - per peers learning; education; quiz; course video; evaluation; skills; competencies; industrial test; ATE programming;

\section{INTRODUCTION}

From 2008 to 2014 , a group of $4^{\text {th }}$ year students from the Electronics department of the engineering school Polytech Montpellier, were trained to the industrial test of integrated circuits (IC) through a project of $28 \mathrm{~h}$ they selected. This project oriented pedagogical approach was organized to have the students being the protagonists of their learning [1], [2]. It allowed teaching IC testing fundamentals and practice to 10 up to 18 students (in binomial groups) without any usage limitations of the operational resources of the CNFM (Coordination Nationale pour la Formation en Microelectronique) [3]. The CNFM is a French public organization that federates academic and industrial partners for the purpose of education in Micro and Nano-electronics. CNFM focuses on making heavy educational resources such as professional CAD tools, clean rooms, or industrial test equipment available for common use, by all French universities and industrial partners. The IC testing course used in particular the industrial test equipment of CNFM center in Montpellier [4].

In 2014-2015, the syllabus was modified and two major changes impacted the industrial test course. First, the reduction of hours: 18 instead of 28, forcing the project oriented pedagogical approach to move to another format keeping the objective of putting the students in the center of learning. Secondly, the course concerned all the $4^{\text {th }}$ year students of the Electronics department, i.e., 28 students instead of an average of 14, generating a bottleneck for the students' practice of the test equipment.

This paper describes the new approach developed to continue teaching industrial test keeping the same educative and technical goals. The section 2 is dedicated to the description of the context of mass production testing, the CNFM test course environment and the test equipment requirements for students' good practice. Section 3 presents the educational approach itself: organization, calendar and dedicated training material, students' and approach evaluation. The analysis of both the students and the pedagogical approach evaluations are provided in section 4 . Section 5 is the conclusion of this return of per peers learning experience.

\section{INDUSTRIAL TEST COURSE}

\section{A. Industrial test of integrated circuits}

Mass production test of Integrated Circuits consists in verifying using automatic test equipment (ATE) a big quality of a product with respect to its specifications. The objective is to detect the defective devices as soon as possible in the device manufacturing cycle in order to decrease the production test cost.

The production test has no other purpose than verifying that manufactured circuits meet the datasheet. Basically, a production test consists in a flow-chart implementation of elementary tests (Test Flow), each having a simple Pass/Fail output (see Fig. 1). Doing so, it is possible to distinguish the failure origin and to perform a sorting (binning) for both good and bad circuits. For instance, this approach is used to sort processors by operating frequencies. The production test is considered right after foundry at the wafer level (wafer sort) and after packaging (final test).

Fig. 1. Test flow example with two "good bins" to sort devices depending

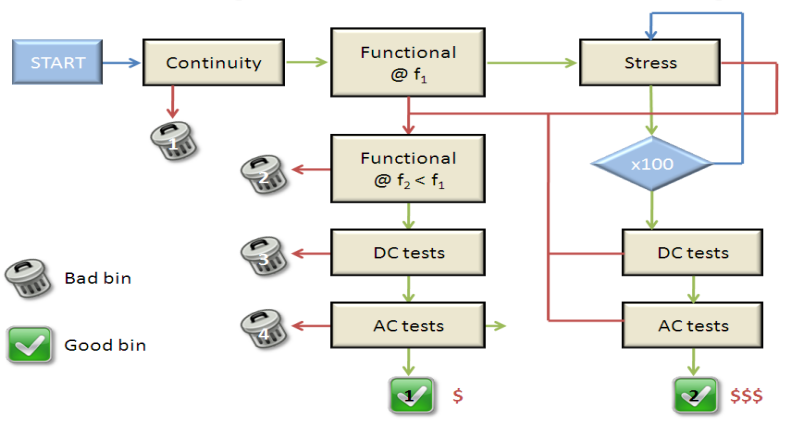


on their performance.

\section{B. CNFM TEST PLATFORM}

\section{1) Tester hardware}

The industrial tester is a V93K from Verigy ${ }^{\circledR}$ recently bought by Advantest ${ }^{\circledR}$, one of the four major test equipment manufacturers in the world. The V93K platform targets SoC (System-on-Chip) products (i.e. Digital, Mixed Signal, RF, embedded memory, etc.) testing.

The basic elements that compose the Automatic Test Equipment (ATE) are illustrated in Fig.2. The main part is the testhead. It can host up to 18 boards (Pin Electronics) for a maximum number of 512 digital pins (or channels) based on existing 32 channels boards. Programming is performed using a regular computer running dedicated software under Linux. Fiber optics is used to allow fast communication between the tester and the CPU.

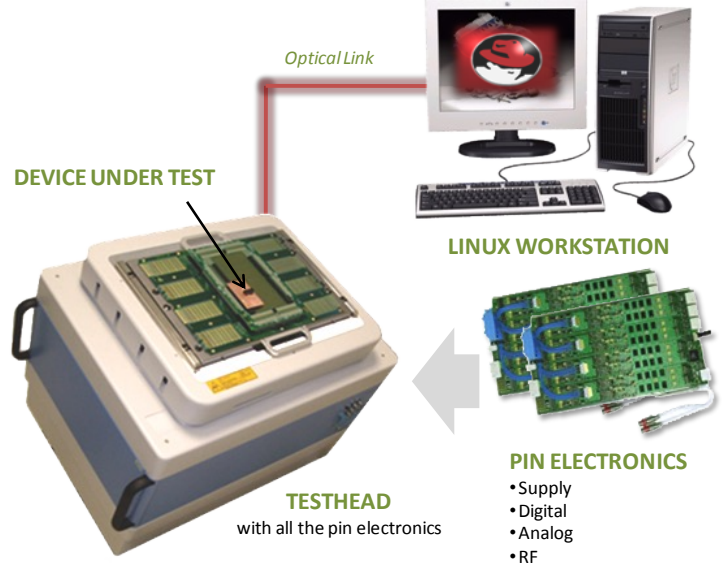

Fig. 2. CNFM test platform main components

\section{2) Tester software and tester virtualization}

The test program is developed into an environment called SmarTest $\AA$, which is based on the open platform Eclipse $\AA$ shown in figure 3.

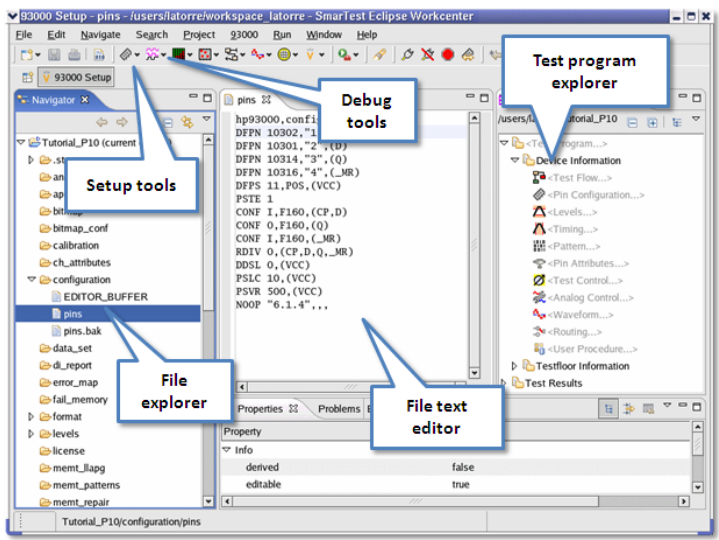

Fig. 3. Smartest ${ }^{\circledR}$ programming environment based on Eclipse ${ }^{\circledR}$ IDE

The software/hardware interaction is built upon the concept of "live-machine". When programming through software, data in the tester memory is continuously updated. The counterpart of this interaction scheme is that the software needs the physical tester to operate. For parallel use in the context of a classroom, the hardware is not divisible and it would lead to a dead end without the availability of an "offline" mode.

In "offline" mode, the tester hardware is emulated in software so that SmarTest ${ }^{\circledR}$ operates just the same as in online mode as long as no real test result is expected. In this mode the students develop their test program and one after the other they move to the "online" mode to verify and correct their test program testing a device. 20 "offline" licenses are available but as Smartest consumes a lot of memory, only 9 of them are run at the same time during students' practice.

Figure 4 represents the network organization of the test platform.

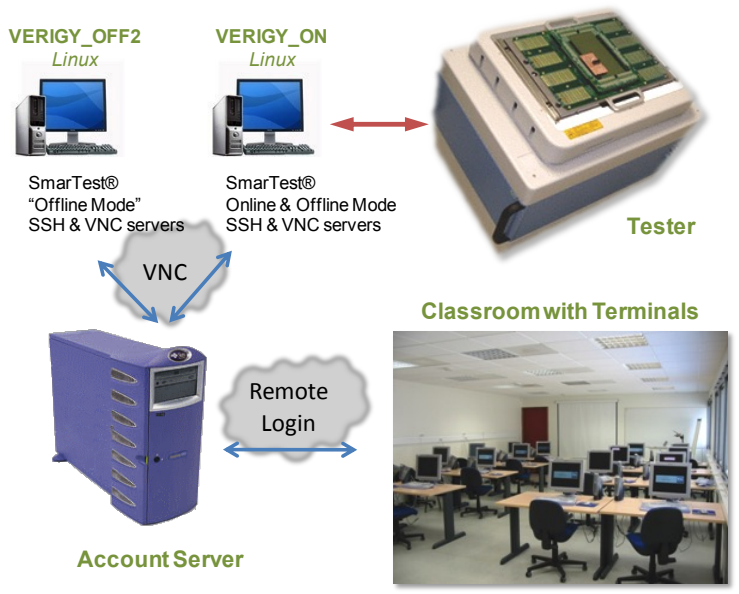

Fig. 4. CNFM test platform environment

VNC technology (Virtual Network Connection) [3] has been used to implement the concept of virtual classroom. This approach allows all students of a class to share their test session, increasing the interactivity between them and the teacher who can help a student having trouble and guide her/him to solve her/his issue.

\section{InNovative Pedagogical Approach Presentation}

\section{A. Choice of the teaching approach}

The main objectives of the course were technical and pedagogical. First, teaching industrial test required lessons to explain the fundamentals, i.e., mass production test philosophy, test method concepts and technics to allow students understanding how the functionalities and performances of integrated circuits are verified. It also required practice (labs) using the test equipment (tester hardware and tester software interface). A solution to solve the mismatch between the number of students (28) and the number of "offline" licenses available for the labs (9) was to gather the students by 3 or $4: 8$ groups of 3 students and 1 group of 4 .

The educational target was to guide the students to be actors of their own learning. With this group configuration (3 or 4 students per group), the challenge was to motivate all group members to fairly contribute to the labs. The solution was to 
select the "per peers learning" approach, in which students teach each other and interact with other students to attain educational goals. This approach was only used to the part of the course needing online access to the tester. It concerned the learning of functional and characterization tests. Faults detection and diagnosis methods were taught to the whole classroom.

\section{B. Educational approach organization}

The idea of using the "per peers learning" technic was to teach one part of the course (lesson and labs) to 18 students (2 students of the 8 trinomial groups and 2 of the group of 4) and a different part of the course to the 10 remaining students (1 student of the 8 trinomial groups and 2 of the group of 4) during 2 sequences of 4 hours for each group. During the next 4 hours (after the 8 first ones), students returned to their original groups, transferred their learning to their peers and all together shared their recent knowledge and know-how to perform labs. The difficulty of this approach was to verify that each student acquired all the technical competencies, meaning the ones taught by the teacher and the ones taught by the peers. The teacher had to anticipate the progress of the course, the potential blocking points in order to schedule a specific calendar that left time for reviews and brainstorming sessions.

This innovative approach also required developing dedicated training materials, like quiz and video tutorials, to help the students successfully achieving the "per peers learning" phase.

\section{Course progress}

1) Step 1: Course presentation to students

The first two hours were dedicated to present:

- The context of mass production test in order to give the students a clear vision of the challenges of testing integrated circuits in the semi-conductors industry.

- The learning objectives, the educational approach, the course organization and calendar (table I), the expected acquired competencies at the end of the course, the students' competencies evaluation mode and the approach evaluation by the students.

It was particularly important to clearly explain the "per peers learning" approach to the students who understood that their peers' learning acquisition of one part of the course depended of their own learning motivation, investment and quality.

At the end of the first step, all the groups were built. Each student knew what she/he will learn from the teacher and will learn from their peers, what she/he will have to teach to peers, the course schedule, the competencies on which he will be tested and that the course will end with a cake party.

TABLE I. INDUSTRIAL TEST COURSE CALENDAR

\begin{tabular}{|c|c|c|c|}
\hline Date & Test session & \# Group & Hrs./student \\
\hline Feb $2^{\text {nd }} A M$ & Introduction \& IC industrialization & $1 \& 2$ & $2 \mathrm{hrs}$ \\
\hline Feb $3^{\text {rd }} A M$ & Test program development & 1 & $4 \mathrm{hrs}$ \\
\hline Feb $17^{\text {th }} A M$ & Characterization test methods & 2 & $4 \mathrm{hrs}$ \\
\hline March $10^{\text {th }} \mathrm{AM}$ & Test program development - end & 1 & $2 \mathrm{hrs}$ \\
\hline March $10^{\text {th }} \mathrm{AM}$ & Characterization test methods - end $\boldsymbol{\lambda}$ & 2 & $2 \mathrm{hrs}$ \\
\hline April $21^{\text {st }} \mathrm{AM}$ & $\begin{array}{l}\text { Per peers learning/ Brainstorming } \\
\text { Common work }\end{array}$ & $1 \& 2$ & $4 \mathrm{hrs}$ \\
\hline April $27^{\mathrm{st}} \mathrm{AM}$ & Common work / Faults diagnostic technics & $1 \& 2$ & $4 \mathrm{hrs}$ \\
\hline April $28^{\text {th }}$ AM & $\begin{array}{l}\text { Quizz, Pedagogical approach evaluation } \\
\text { by the students \& Cake time }\end{array}$ & $1 \& 2$ & $2 \mathrm{hrs}$ \\
\hline
\end{tabular}

2) Step 2: Classic learning: teacher to both groups of students

During two sessions of 4 hours, the teacher taught to group $\mathrm{n}^{\circ} 1$ composed of 18 students (grouped by 2 ) and to group $\mathrm{n}^{\circ} 2$ composed of 10 students (standalone student) different aspects of the industrial test of integrated circuits. Group $n^{\circ} 1$ learnt the basics of functional testing: study of the device under test, initiation to tester hardware and software interface (Smartest ${ }^{\circledR}$ ), learning of the functional test method, the test flow concept and their implementation on tester. Group $n^{\circ} 2$ learnt the basics of characterization: parametric tests to verify the AC and DC parameters of a device data sheet, test results analysis and margins calculation, shmoo plots technics and graph interpretation to identify any parameter dependency, any malfunctioning at uncovered test conditions during mass production.

At the beginning of the second session, a short brainstorming was proposed to each group in order to status on their knowledge, know-how and gaps. To ease the communication, colored post-it papers have been distributed to all students. They had to write down the misunderstood and put them on a white board. The teacher gathered the post-it papers by item and answered them once he was sure to have understood the request. May be the funny aspect of the post-it papers and the anonymous process contributed to motivate the students to actively participate. Any gap was explained.

At the end of the 8 hours, both groups answered to a quiz whose objective was to help them facing the level of their acquired competencies before teaching their peers. Once again any misunderstanding was explained again.

3) Step 3: Per peers learning

Unfortunately, more than a month had passed by since the last session with group $n^{\circ} 2$. To guaranty the success of per peers learning it was crucial that the topics learnt by the students from both groups were fresh in their mind. So, the first $1 / 2$ hour of the 4 hours session was dedicated to the review of both groups learning acquisitions. Two classrooms were booked to ease this step. The teacher provided to group $n^{\circ} 1$ and $n^{\circ} 2$, the list of skills all students from group $n^{\circ} 1$ must be able to teach the students from group $n^{\circ} 2$ and vice-versa. Because the tester software interface SmarTest ${ }^{\circledR}$ offers a lot of possibilities and is complex to apprehend when not used every day, the teacher provided to the students from group $\mathrm{n}^{\circ} 1$ a series of videos created with Camtasia ${ }^{\circledR}$ software, in order to help them remembering the usage of $\operatorname{SmarTest}{ }^{\circledR}$. Each video was a record of a command of the tester interface needed to create a test flow or a single test, completed with visual comments describing the different steps of the usage. The teacher provided a guideline to group 2 remembering how to proceed to analyze shmoo plots (variation of 2 test parameters at the same time).

Then the original 8 trinomial groups and the group of 4 students gathered in the same classroom and the per peers learning process started following the organization and schedule:

- 4 trinomial groups and the group of 4 students worked on teaching the functional test methods and practicing using the offline mode of the test equipment while 4 trinomial 
groups concentrated on teaching characterization test skills during $1 \mathrm{~h} 30$.

- 15 minutes break

- 4 trinomial groups and the group of 4 students worked on teaching characterization skills while 4 trinomial groups concentrated on teaching the functional test methods and practicing using the offline mode of the test equipment during $1 \mathrm{~h} 30$.

- 15 minutes debriefing at the end of the course

The teacher did not give the students any guideline to teach their peers to respect their own process and rhythm but paid attention to the way each group worked.

4) Step 4: Classic learning: teacher to all students

During the 2 hours of the next session, all students were initiated to fault detection method and tools and, following a given diagnosis procedure they learnt how to proceed to identify the root cause of a defect. The main objective was to raise the students' awareness to physical defects that can affect digital devices. The students had to diagnose 5 test reports each representing the detection of one defect coming from the introduction of one stuck-at fault on one pin of the device under test. Students had to share their answers before the teacher randomly selected students to explain the solution of the exercise.

\section{5) Students' learning skills evaluation}

The students were evaluated on the test concepts and technics, tester interface commands, shmoo plot graph analysis and faults diagnosis. The exam was a 1-hour quiz (10 questions) and 3 exercises (shmoo plot graph analysis and stuck-at fault diagnosis). Almost all questions had been treated during the course or during the review phase through the quiz. It was the same approach for shmoo plot graphs analysis and faults diagnosis exercises.

This choice of exam mode was based on a remark made by Antoine de la Garanderie on p48 of his book [7]: "We have the past (knowledge and know how) only as much as we take care of registering it in the future (when we learn)". This author studied the learning methods used by very good students and concluded that they learnt projecting their new learning in the context they would need it, like an exam, avoiding stress and knowing exactly where to search for it in their brain memory. In our case, the objective was to put back the students in a context they knew (the time when they learnt in-group or when they performed the quiz during the review phase) to limit the emotions coming from the stress of the exam and to allow their brain concentrating on reactivating their competencies.

In order to avoid the students to copy each other, 3 versions of the exam were created.

6) Educational approach evaluation by the students As students from group $\mathrm{n}^{\circ} 1$ learnt the basics of functional testing from the teacher and the characterization competencies from group $\mathrm{n}^{\circ} 2$ peers and students from group $\mathrm{n}^{\circ} 2$ learnt characterization competencies from the teacher and the basics of functional testing from group $n^{\circ} 1$ peers, it was important to write a dedicated evaluation form that allowed identifying and measuring any skills level mismatch resulting from a same topic taught by the teacher and peers. A second aspect of the evaluation form concerned the students' feedback about the learning in-group method. The overall document was based on an evaluation form from FA2L Louvain teachers [8].

- The document was organized as follow:

1. Student self-evaluation on her/his learning with the teacher and the teaching approach itself

2. Student self-evaluation on her/his learning with peers and the per peers learning approach

For these 2 self-evaluations, the students had to fill tables in which they had to rank their level of knowledge and know-how on topics taught by the teacher and their peers. To evaluate both teaching approaches, they had to provide their level of satisfaction concerning the course organization, the allocated time for lessons, practice and per peers learning and, the relevance of the quiz and Camtasia ${ }^{\circledR}$ videos usage.

3. Trinomial group and group of 4 students' evaluation of the per peers learning approach using a spider diagram (see figure 5)

4. Students' self-feedback about the advantages and disadvantages of working in-group to learn skills.

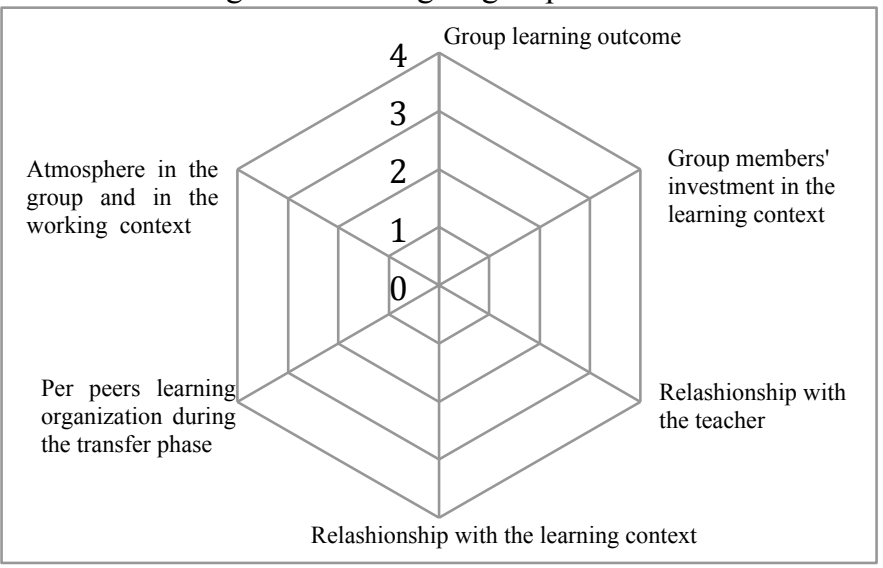

Fig. 5. Spider diagram for the "per peers learning" approah evaluation by

7) Cake party the groups of students

The teacher proposed a cake party to celebrate the end of the course. All students brought food and beverages and shared them as shown on the figure 6 .

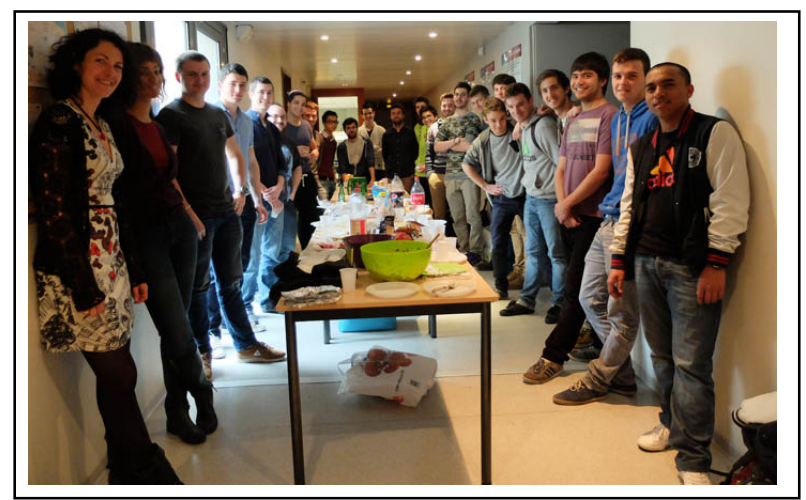

Fig. 6. Polytech MEA4 students - April 2015 


\section{EDUCATIONAL APPROACH OUTCOMES}

\section{A. Analysis of students' exam results}

The final mark of the exam was the sum of the quiz marks and the ones from the 3 exercises:

- 10 points for the 10 questions quiz

- 3 points for the shmoo plot analysis

- 3 points for the stuck-at fault identification

- 4 points to insert a stuck-at fault on a device and indicate in a test vector the faulty cycles and outputs

Over the 28 students who attended the industrial test course, 13 of them got a mark between 16,2/20 and 20; 8 of them got a mark between 15/20 and 16,14/20 (average value) and 7 of them got a from $11,5 / 20$ up to $14,5 / 20$. The details of the marks are listed in the table II.

TABLE II. STUDENTS' MARK DETAILS

\begin{tabular}{|c|c|c|c|c|c|c|c|}
\hline $\begin{array}{c}\text { Stude } \\
\text { nt \# }\end{array}$ & $\begin{array}{c}\text { Grou } \\
\text { p \# }\end{array}$ & $\begin{array}{c}\text { Mark } \\
\mathbf{s} \\
\end{array}$ & $\begin{array}{c}\text { Quiz } \\
\#\end{array}$ & $\begin{array}{c}\text { Quiz } \\
\text { Marks } \\
\text { (10) }\end{array}$ & $\begin{array}{c}\text { Shmoo } \\
\text { Marks (3) }\end{array}$ & $\begin{array}{c}\text { Diag } \\
\text { Marks } \\
\text { (3) }\end{array}$ & $\begin{array}{c}\text { Fault } \\
\text { Marks } \\
(4) \\
\end{array}$ \\
\hline 1 & 1 & 19 & 1 & 10 & 3 & 3 & 3 \\
\hline 2 & 1 & 13,5 & 1 & 7,5 & 2 & 1 & 3 \\
\hline 3 & 1 & 18,5 & 1 & 9 & 2,5 & 3 & 4 \\
\hline 4 & 1 & 17,5 & 1 & 9 & 1,5 & 3 & 4 \\
\hline 5 & 1 & 18 & 1 & 9 & 2 & 3 & 4 \\
\hline 6 & 1 & 15,75 & 2 & 8,25 & 1,5 & 2 & 4 \\
\hline 7 & 1 & 17,5 & 2 & 9,25 & 2,75 & 2 & 3,5 \\
\hline 8 & 1 & 11,75 & 2 & 8,75 & 2 & 1 & 0 \\
\hline 9 & 1 & 18,5 & 2 & 10 & 2,5 & 2 & 4 \\
\hline 10 & 1 & 11,5 & 2 & 8 & 1,5 & 0 & 2 \\
\hline 11 & 1 & 19 & 2 & 10 & 3 & 2 & 4 \\
\hline 12 & 1 & 15,5 & 2 & 9 & 2,5 & 1 & 3 \\
\hline 13 & 1 & 15,5 & 2 & 9 & 1,5 & 2 & 3 \\
\hline 14 & 1 & 15 & 2 & 8 & 0 & 3 & 4 \\
\hline 15 & 1 & 15 & 3 & 8,5 & 3 & 1 & 2,5 \\
\hline 16 & 1 & 20 & 3 & 10 & 3 & 3 & 4 \\
\hline 17 & 1 & 17 & 3 & 10 & 3 & 1 & 3 \\
\hline 18 & 1 & 15,75 & 3 & 9 & 2,75 & 2 & 2 \\
\hline 19 & 2 & 15 & 3 & 9 & 3 & 0,5 & 2,5 \\
\hline 20 & 2 & 17,5 & 3 & 10 & 2 & 2 & 3,5 \\
\hline 21 & 2 & 16,5 & 3 & 9 & 3 & 1 & 3,5 \\
\hline 22 & 2 & 14,25 & 3 & 8,5 & 2,75 & 2 & 1 \\
\hline 23 & 2 & 15,5 & 3 & 9,5 & 0 & 3 & 3 \\
\hline 24 & 2 & 19 & 3 & 10 & 3 & 2 & 4 \\
\hline 25 & 2 & 13,5 & 1 & 10 & 0 & 2,5 & 1 \\
\hline 26 & 2 & 14,5 & 1 & 5,5 & 3 & 3 & 3 \\
\hline 27 & 2 & 12 & 1 & 8 & 2,5 & 0,5 & 1 \\
\hline 28 & 2 & 20 & 1 & 10 & 3 & 3 & 4 \\
\hline
\end{tabular}

As a reminder, group $n^{\circ} 1$ learnt functional test skills from the teacher and the characterization ones from their peers; group $\mathrm{n}^{\circ} 2$ acquired characterization competencies from the teacher and functional test ones from their peers.

The columns called "Quiz marks" and "Shmoo Marks" were relative to "per peers learning". The columns called "Diag Marks" and "Fault Marks" concerned lessons given by the teacher to the whole class.

Looking at the $2^{\text {nd }}, 3^{\text {rd }}$ and $4^{\text {th }}$ columns of the table II, questions appeared about the influence of the teaching approach (teacher versus peers reflected by the 2 groups) and/or the quiz subject number even if the 3 versions of the quiz were randomly distributed to the students.
The extraction of the marks versus the quiz version is presented in the table III as well as the group number: 1purple, 2-yellow. The average and standard deviation values of each quiz version were calculated in order to have an idea of the marks distribution around the average value. The number of students from both groups who answered to quiz version 1 was fairly the same. The average value of this quiz is quite high and its standard deviation is the biggest with almost 3 points. It was random but it appeared that quiz version 2 had been only answered by group $n^{\circ} 1$ students which got the lowest average value but not the biggest standard deviation. Finally, quiz version 3 which had fairly the same number of students from both groups scored the best with the lowest standard deviation. As there was no obvious evidence, we concluded that the quiz version did not influence the marks.

TABLE III. MARKS VERSUS QUIZ VERSION COMPARISON

\begin{tabular}{|c|c|c|c|}
\hline & Marks/quiz 1 & Marks/quiz 2 & Marks/quiz 3 \\
\hline & 19 & 15,75 & 15 \\
\hline & 13,5 & 17,5 & 20 \\
\hline & 18,5 & 11,75 & 17 \\
\hline & 17,5 & 18,5 & 15,75 \\
\hline & 18 & 11,5 & 15 \\
\hline & 13,5 & 19 & 17,5 \\
\hline & 14,5 & 15,5 & 16,5 \\
\hline & 12 & 15,5 & 14,25 \\
\hline & 20 & 15 & 15,5 \\
\hline & & & 19 \\
\hline Total & 146,5 & 140 & 165,5 \\
\hline Average & 16,27777778 & 14 & 16,55 \\
\hline Std Dev & 2,905932629 & 2,63621941 & 1,851425877 \\
\hline
\end{tabular}

Nevertheless if the number of group $n^{\circ} 1$ students were almost twice the number of group $n^{\circ} 2$ students, it seemed that the marks from this latter group were slightly lower than the ones from the former. Table III displays the extraction of the average marks and the standard deviation versus the group number.

TABLE IV. MARKS VERSUS GROUPS COMPARISON

\begin{tabular}{|c|c|c|}
\cline { 2 - 3 } \multicolumn{1}{c|}{} & Marks/gp 1 & Marks/gp2 \\
\hline Average & 16,34722222 & 15,775 \\
\hline Std Dev & 2,437662346 & 2,490119363 \\
\hline
\end{tabular}

Focusing on table IV, it appeared again that both average and standard deviation values of each group were similar, showing no obvious evidence of the influence of the teaching methods. In order to go further, the details of the quiz marks and the shmoo plot exercise were studied per group number.

The shmoo plot lesson was given by the teacher to group $\mathrm{n}^{\circ} 2$ students and they taught their peers from group $n^{\circ} 1$. The average values resulting from the 18 marks of group $n^{\circ} 1$ and 10 ones from group $n^{\circ} 2$ shown $0,12 \%$ difference, which was irrelevant.

Focusing on the quiz questions, we studied the influence of the questions relative to the competencies given to both groups directly from the teacher and the ones from the "per peers learning" approach. In Table V, Quiz Q1 column represents the questions relative to competencies taught by the teacher to group $n^{\circ} 1$, so students from group $n^{\circ} 2$ learnt these skills from 
their peers. Consequently, Quiz Q2 column represents the opposite. This time, a small difference between the skill levels appeared pointing out that the students who learnt skills from the teacher had slightly higher marks.

TABLE V. COMPARISON OF TEACHING APPROACHES

\begin{tabular}{|c|c|c|}
\hline & Quiz Q1 & Quiz Q2 \\
\hline Average marks/gp 1 & $\mathbf{5 , 7 5}$ & 3,333333333 \\
\hline Average marks/gp 2 & 5,45 & $\mathbf{3 , 6 5}$ \\
\hline Ratio average gp/gp \% & 5,217391304 & 8,675799087 \\
\hline
\end{tabular}

In fact, this difference did not result from the teaching method itself but rather from the time allocated to each one: both groups spent 8 hours learning from the teacher and only 6 hours from their peers. In addition, group $n^{\circ} 1$ students had the challenging mission to explain group $\mathrm{n}^{\circ} 2$ students how to use the tester interface tool SmarTest ${ }^{\circledR}$ which was complex task.

\section{B. Analysis of the students 'teaching approach evaluation}

The collection of the students' answers about their learning experiences with the teacher and peers and their level of acquired skills were first analyzed. The objective was to point out any major skill levels difference between both teaching methods on a same topic based on students' feedback and not marks. The analysis shown that students who considered having a lower acquisition level on a topic with the per peers approach mentioned that it was the consequence of the lack of time allocated to this innovative teaching method and not due to the approach itself.

In general, the students liked the "per peers learning" approach because it gave them a new role: being the actor of their peers' learning. It meant that they had to take written notes and be pro-active during the course session with the teacher in order to understand, ask questions if necessary and memorize the concepts, technics and practice. Most of the students realized that they were not enough concentrated during the lessons and met difficulties reminding what they learnt. They also realized that their learning was not complete only when they started teaching their peers and had difficulties to explain some topics.

They mentioned that not enough time was dedicated to per peer learning session and they would have preferred to follow a procedure to teach their colleagues. The students considered that teacher's choice not to provide them a guideline during the transfer phase to respect their own teaching rhythm was not appropriated. It influenced the acquired knowledge and know-how levels.

Students would have liked to have a review session after per peer learning one to be sure to have acquired all necessary skills and competencies.

Students would have liked to have more time to practice on the tester to get familiar with its usage and the complexity of its interface. They also mentioned a lack of time allocated to shmoo plots explanation and practice.

They liked having Camtasia ${ }^{\circledR}$ videos to review the tester interface usage and they also appreciated the quiz, during the course, to evaluate their own knowledge.
They considered that there was too much time between to 2 test courses that did not ease remembering their learning.

\section{Improvements}

The major improvements to apply to this innovative education approach concern the "per peers learning" part:

- To write a dedicated procedure to guide the students (who want to use it) teaching their peers.

- To give a quiz to the students at the end of the "per peers learning session" to verify all students have acquired all the required skills and competencies. The procedure would to have each student answering the question alone, then, the responses would be shared and discussed with peers, before questioning the teacher.

A last improvement would be to have only a week delay between each test course.

\section{CONCLUSION}

This paper presented a return of experience relative to a "per peers learning" approach to teach industrial test of integrated circuits (IC) to $4^{\text {th }}$ year students from Polytech Montpellier, using the test platform of the CNFM.

From pedagogical point of view, it was an interesting experience because students get quickly motivated and ready to succeed their "teaching mission". For the teacher, it was very time consuming, as it was regularly necessary to adjust the course organization to fit the calendar and learning objectives. It also required a lot of efforts to create appropriated training materials. Nevertheless, most of them are reusable with other students or teachers, which is a real benefit.

Some improvements will be applied to the "per peers learning" approach to guaranty no skill level mismatch between competencies learnt from the teacher and the peers. This innovative teaching method has been put in place to solve technical issues (tester licenses number) but it clearly appeared that it could be apply to other courses.

\section{REFERENCES}

[1] Beatrice Pradarelli, Pascal Nouet, Laurent Latorre, "Une pédagogie par projet pour des étudiants acteurs et auteurs de leur apprentissage", VIII ${ }^{\circ}$ colloque QPES, Brest 17-19 juin 2015, pp 378-384, ISBN 978-29553298-0-1

[2] Beatrice Pradarelli, Pascal Nouet, Laurent Latorre, "Industrial Test Project Oriented Education", EDUCON 2016, April $10^{\text {th }}-13^{\text {th }} 2016$ Abu Dhabi, in press

[3] See: www.cnfm.fr.

[4] See/cmos.cnfm.fr

[5] Xiaolin $\mathrm{Lu}$, "Construct Collaborative Distance Learning Environment with VNC Technology", Semantics, Knowledge and Grid, 27-29 Nov. 2005, pp.:127-130.

[6] See: https://www.techsmith.com/camtasia.html

[7] Antoine de la Garanderie: "Réussir ça s'apprend" (Learning how to succeed)

[8] See: http://fa2l.weebly.com 